\title{
An architectural assessment method for new exterior additions to historic buildings
}

\author{
Hülya Yüceer ${ }^{\mathrm{a}, *}$, Başak İpekoğlu ${ }^{\mathrm{b}}$ \\ a Department of Architecture, Faculty of Architecture, Eastern Mediterranean University, Gazimagusa, via Mersin 10, Turkey \\ ${ }^{\mathrm{b}}$ Department of Architectural Restoration, Izmir Institute of Technology, Faculty of Architecture, 35430 Izmir, Turkey
}

\section{A R T I C L E I N F O}

\section{Article history:}

Received 23 May 2011

Accepted 7 December 2011

Available online 21 January 2012

\section{Keywords:}

Architectural conservation

Architectural assessment

Contemporary additions

Historic buildings

Historic building assessment

\begin{abstract}
A B S T R A C T
The design approaches of new exterior additions to historic buildings have been among the ongoing debates in the field of architectural conservation. The aim of this study is to develop an assessment method, which can be used to determine the compatibility in architectural expression of the new addition in relation to the characteristics of a historic building. This method is based on the architectural analysis, which includes environmental relations, building-lot relations, mass relations and the facade composition of the historic building both before and after the new addition in relation to the value of a historical building. In this study, a selected group of historic buildings in İzmir, Turkey with new exterior additions was analysed with regard to their exterior architectural characteristics in order to evaluate the compatibility of the new addition, by employing the use of contemporary conservation principles. The importance of this study is to guide architects to form the basis of a decision for developing an integrated approach in designing new additions in the course of the actual design process. On the other hand, the proposed method can be evaluated as a contribution to the emerging field of heritage impact assessments as well as scientific assistance to local governments to criticize specific projects of cultural heritage assets submitted for appraisal. Analysis results showed that the value of the historic building should first clearly be identified and a new addition should bear the identity of its own period. However, instead of altering the scale or form of the historic building, a new addition should complement and contribute to the sense of proportion, disposition and historical pattern.
\end{abstract}

(c) 2012 Published by Elsevier Masson SAS.

\section{Research aims}

This article presents an assessment method to determine the compatibility of a new addition to a historic building. Based on architectural analyses which were applied to a selected group of historic buildings with exterior additions, this research aims to identify coherent issues to be taken into consideration during the design process of a new addition to a historic building by the use of a developed method, and it is intended to form a scientific assistance tool for architects in decision-making process and for local governments to criticize specific projects of cultural heritage assets submitted for appraisal. This research also aims to contribute to the emerging field of heritage impact assessments through the developed method, which outlines alternative design approaches that could be applied, based on a range of decision-making factors.

\footnotetext{
* Corresponding author. Tel.: +90 39263022 24; fax: +90 3926302325.

E-mail addresses: hulya.yuceer@emu.edu.tr (H. Yüceer), basakipekoglu@iyte.edu.tr (B. İpekoğlu).
}

\section{Introduction}

One of the concerns of architectural conservation is the adaptation of historic buildings to the changing requirements of the present day. As the historic buildings were created with the techniques and according to the conditions of a past period, their adaptation processes require interventions at various levels [1]. Although it is appreciated that it is vital to keep interventions at a minimum in order not to reduce the value of the historic building, the degree of intervention may increase due to the expectations from its restoration. New exterior additions are considered as major interventions that are designed to either attach to the historic building or be situated within the boundaries of the historic building's lot. Regardless of its scale, a new addition to a historic building comprises the problem of establishing an appropriate relation between traditional and contemporary architectural language. Different approaches to the issue of evaluating new additions to historic buildings have been considered previously $[2,3]$. In these researches, additions to historic buildings were examined and discussed in terms of architectural criteria and the identity of the historic building. In the framework of this study, an assessment method has been developed to determine the compatibility 


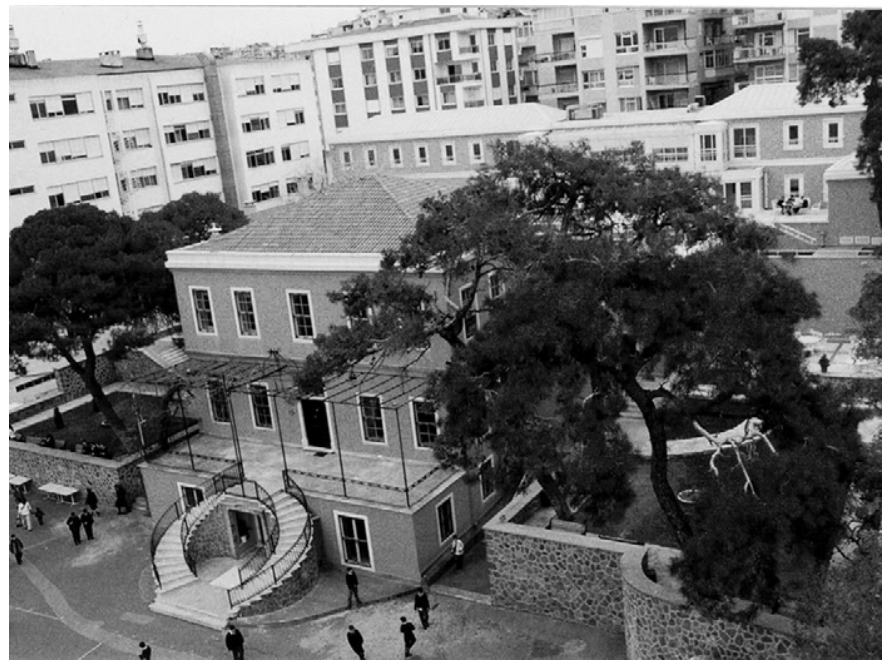

Fig. 1. Uşakizade Mansion.

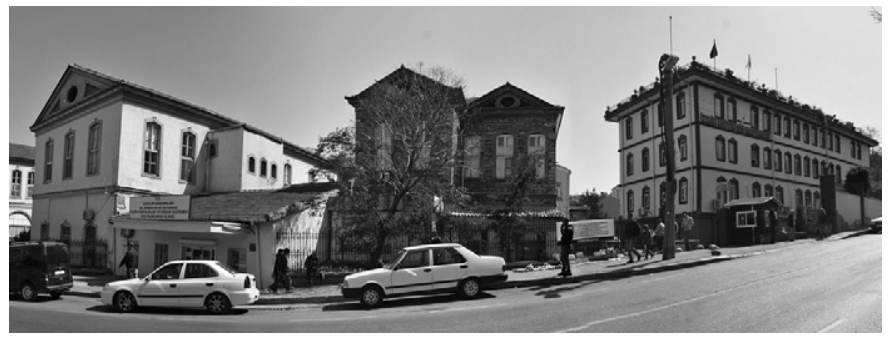

Fig. 2. Konak Public Hospital.

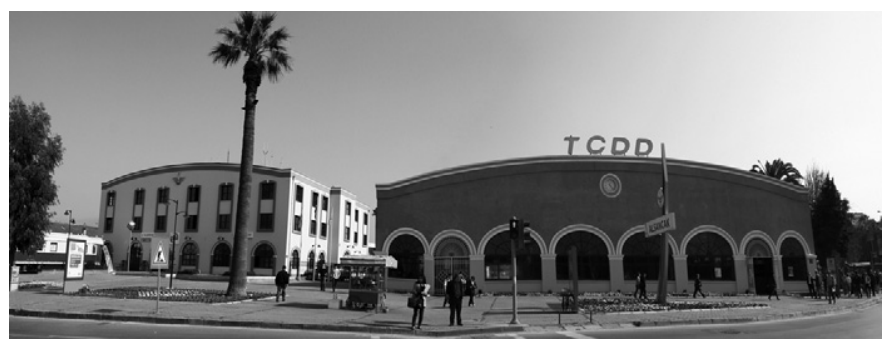

Fig. 3. Alsancak Train Station.

of a new addition to a historic building [4,5]. This method is based on architectural analyses dependent on the criteria that have already been considered in previous studies as well as international charters and national guidelines [6-11]. These analyses include environmental relations, building-lot relations, mass relations and the facade composition of the historic building both before and after the new addition. In the context of this study, a selected group of historic buildings with new exterior additions in İzmir, Turkey was analysed in order to evaluate the appropriateness of the new addition by employing the use of contemporary conservation principles. The buildings under consideration are the Uşakizade Mansion (Fig. 1), the Alsancak Public Hospital, Konak Public Hospital (Fig. 2), Alsancak Train Station (Fig. 3), the School for the Deaf and Blind and Pasaport Quay. The examples were selected according to the following criteria: with respect to the condition of the historic building before the intervention, the building should be intact, so that the intervention does not aim to replace or complete any missing parts of the historic building. The additions should go beyond the boundaries of the existing parameters of the original building, either adjacent to or connected to the mass of the historic building and should be designed according to the rules and regulations of an architectural conservation project, which confirms the requirements of the commissions entitled to accept or reject the application of the restoration criteria.

It is possible to identify the issues to be taken into consideration both in the determination of the limits of an intervention and in making appropriate design decisions for any exterior additions using this method. Results have demonstrated that the assessment method developed in this study can be used as a guide for architects to evaluate the existing new additions to historic buildings and to form a basis, which supports the decision of the approach to follow with respect to the new additions during the design process. On the other hand, the proposed method can be evaluated as a contribution to the emerging field of heritage impact assessments [12] as well as scientific assistance to local governments to criticize specific projects of cultural heritage assets submitted for appraisal.

\section{Determination of assessment criteria}

The evaluation should primarily be based on the analysis of the historic building in question as a part of architectural heritage. Therefore, together with the architectural characteristics, the values that make the building eligible for preservation should clearly be defined. In the later phase, the contemporary addition itself requires evaluation as an architectural product designed with reference to a historic building. However, the new addition should bear the principle of reversibility, i.e., it should be designed in order not to damage details ornamentation and junctions between itself and the existing historic building when it is removed if necessary in the future. In defining the values and characteristics of both the historic building and the new addition, the evaluation must establish certain criteria to be adopted in the formation of the language between two edifices.

\subsection{Criteria for architectural analysis}

With regard to the conceptual framework of this study, the tangible aspects of the architectural edifice will be considered, which is also limited by its external appearance. The basic tangible aspects are identified as the environment and setting, the site, the mass, the facade order including the architectural detailing and ornamentation of the exterior surface.

\subsubsection{Analysis of a building in relation to its environment and setting}

An exterior addition is mostly associated with the rising demand for extra space or for functional change especially for the old public buildings in fast growing cities. Possessing strong architectural features of their location in history, such buildings have influenced the formation of the overall character of their surroundings [13]. The issue of the setting of a building and the protection of the setting arises in the wording of the Venice Charter as an imperative for protection [10]. Not only does the building suggest a particular historical association, but also the environment in which it is located. Any change in that setting could result in a distorted or different interpretation of the apparent significance of the building.

Thus, in designing an exterior addition, the architect's challenge is to create and develop an approach, which does not harm or detract from the historic character of both the existing structure and its surroundings while creating an identity, which is representative of the contemporary period. In the analysis of the building in relation to its immediate environment, the basic physical characteristics of the surrounding buildings such as their height and function are considered. The location of the historic building in the city, its appearance and visibility from the main 
thoroughfares and its accessibility are the criteria for the analysis of an historic building both before and after a new addition.

\subsubsection{Analysis of a building in relation to its site}

The landscape surrounding a historic building and its individual lot are considered as the building's site. Horizontal additions to historic buildings affect the solid-void relation in particular, since they occupy the original open space of the building lot. As most of the exterior additions are constructed horizontal to the historic building and are either attached or detached, they particularly interfere with the relation of the building to its own lot. Buildinglot relations may depend on the number of buildings on the lot, the building order, the location of buildings in the boundaries of the lot, the orientation or specific location of buildings with each other, and the use of open space. Therefore, the analysis should be carried out with respect to the building's original relation with its lot and its relation following the addition.

\subsubsection{Analysis of mass}

In architectural terminology, the term "mass" is used to define the three-dimensional bulk of a building and it consists of the building's height, width, and depth [14]. The mass of a building is the first impression of a building for a person. The major contributors to a building's overall character are embodied in its distinguishing physical aspects without focusing on its details [15]. The location, setting and orientation of a mass are also important factors in considering visual analysis of the exterior of a building [16]. The orientation of a building can be defined as the position, presentation and direction of the facades on its site in relation to its surroundings [17]. In this context, the configurations of the established site and the relationship of the building to the site boundaries, its prevailing orientation, its position in relation to streets in the area and the integration of that position within the new addition should be taken into consideration.

A further criterion for the analysis of the mass of a building is the building scale, which may be defined as the size and proportion of it, in relation to the surrounding buildings and development in the area, the adjacent streets, and pedestrians [14]. Depending on its specific conditions of architectural identity, its functional programme and location, the composition of mass is also affected by structural constraints. The structural features of a building may offer an opportunity for exterior expression, although they may also be seen as a means of interior expression [18]. The analysis of mass includes the form, the height, the proportions, the type of superstructure, the structural system and materials of the building.

\subsubsection{Analysis of facades}

The facades of a building are the most essential elements in the exterior analysis. The facade is not only the representation of the interior, but it also reflects the cultural features of the period when the building was built [19]. Components of the facade are the roof, windows, doors, details and ornamentation which are different in terms of form, materials and colours. The composition is the language binding them to the whole, while each component offers an identifiable individuality [18]: The visual components constitute a logical basis for organizing the building into manageable parts in order to offer an exterior analysis. Separate analysis of each component provides an opportunity to isolate the building's various parts, describe its visual characteristics and quality, and identify visual assets and liabilities. The components of the facade can be analysed with reference to their number, rhythm, placement, form, proportions, divisions, units, type, material, surface material and ornamentation [17]. The exterior surface material is the final touch in the design of a facade. The choice of the surface materials for new additions is important because of its high visibility [11]. Moreover, exterior surface finishes provide colour for buildings depending on the materials used. For instance, stucco, stone or wood, as well as, paint can add visual interest to a new addition. Furthermore, the choice of colour affects the site with respect to the new addition. Thus, the exterior surface should be analysed by considering the texture and colour of the finishing material.

\subsection{Criteria for value analysis}

Since the starting point of conservation studies is based on the definition of the significance of the historic building, the identification of this significance has an essential value for the design process of the new addition. Therefore, it should not harm any of those significant values. Identifying the features that give a building its historic significance refers to all its tangible and intangible aspects [20]. The following criteria have been developed in respect of the value and worth of the building attributed to it according to the degree of its architectural importance, cultural importance, contextual importance, authentic importance and contemporary importance.

\section{Assessment of the sample building}

\subsection{General characteristics of the sample building}

The six sample buildings studied in the content of this study were chosen in the downtown İzmir that is located on the Aegean Coast of Turkey. The Uşakizade Mansion examined in this article was formerly a residential building and then it was converted into a building for educational purposes. Although the exact construction date of the Mansion is not known, the records of the owner and the architectural characteristics of the building reveal that it was built in the second half of the 19th century. The building has the family name of the owner and the builder who have migrated from the province of Uşak and settled in İzmir at the beginning of the 19 th century. With the amendment of the surname act, the family members have chosen the surname of Uşakizade (meaning from Uşak) as their surname and from then on, the Mansion has been called by the family name. Another name used for this building is the Latife Hanim Mansion, which also refers to an important historical event. Latife was daughter of the owner who was later married to Atatürk, the founder of the Turkish Republic. During the War of Independence, this building was used as the headquarters by Atatürk and his military staff. However, when their marriage ended in 1925, Atatürk's relationship and/or connection with this Mansion also came to an end.

Since 1950, the Mansion was only used by its owners as a summer villa. Afterwards it was sold to the Tatiş family, and in the following years, it was used as a private school. The building has a specific place in the memories of the citizens of Izmir as the Turkish College since it is one of the earliest private schools in İzmir. In 1991, the first attempts to change the function of the building into a museum and cultural centre as part of Izmir Turkish College began and the construction of the new addition and the restoration of the Mansion carried out between 1999 and 2001.

The area where the building is located housed several historical, residential buildings, most of which were later demolished and replaced by new multi-storey buildings. However, a few historic residences reflecting the typical architectural characteristics of the 19th century İzmir remain.

\subsection{Analysis and assessment of the sample building}

The architectural analysis of the building includes the analysis of the environmental relations, the building-lot relations, mass relations and the analysis of its facades. 

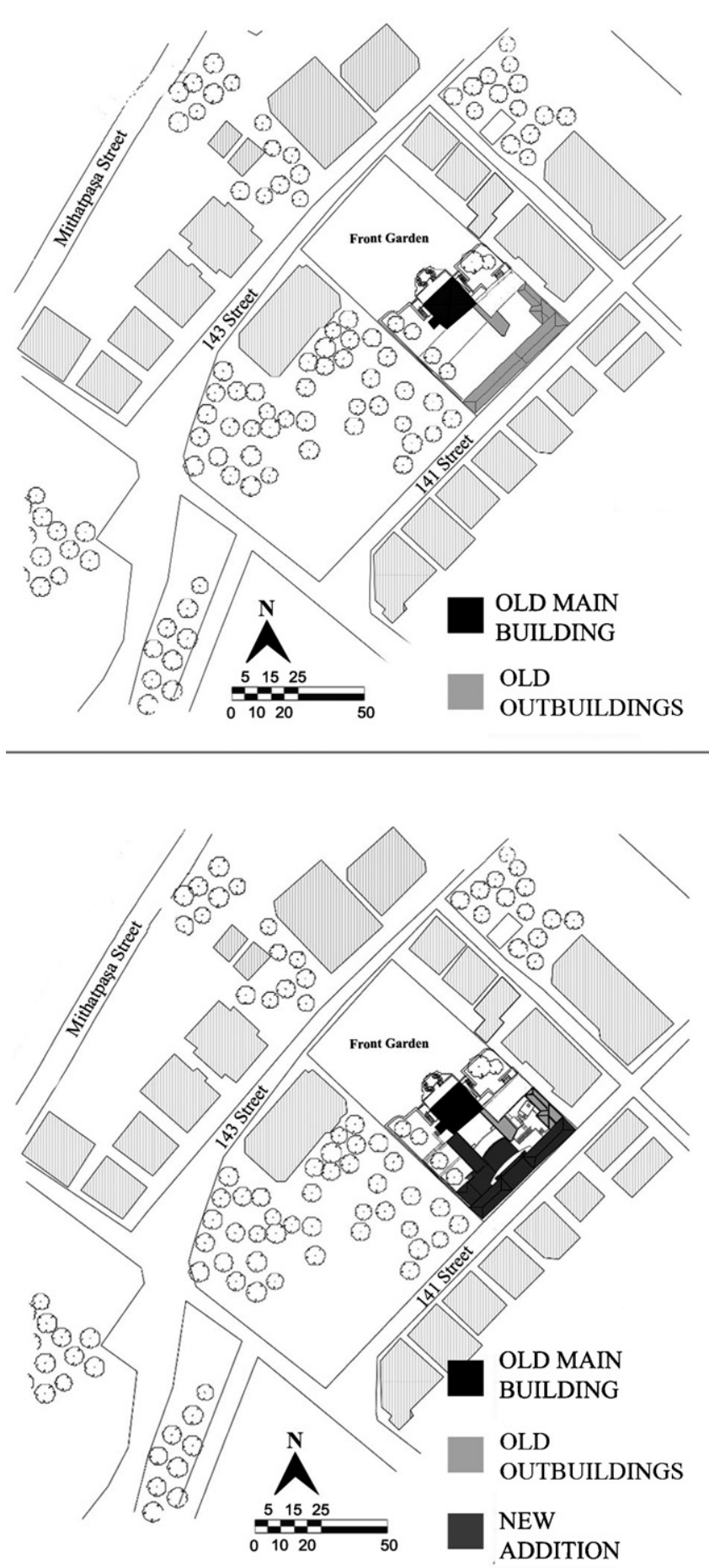

Fig. 4. The relation of the building with its setting before and after addition.

\subsubsection{Assessment of environmental relations}

The main entrance to the building lot is from the west side facing the sea and the main orientation of the Mansion is towards the west. The garden in front of the building is larger than the one at the back (Fig. 4). The topography of the site slopes in an east-west direction and the east end of the lot is higher than that of the west. Thus, the best view of the building is from the west. These data were used to determine the location of the new addition, which was constructed parallel to the boundary of the lot at the backside. With the introduction of the new addition:
- since the new addition was constructed at the back of the old building, the perception of the historic building from the main facade was not blocked;

- the relation of the old building to its environment and the visual contact is not disturbed as the new addition is lower than the old building.

\subsubsection{Assessment of building-lot relations}

Before the new addition, there was a one-storey outbuilding attached to the rear facade of the Mansion, which was located parallel and perpendicular to the main building with an L-shaped form (Fig. 5). The new addition is partially constructed onto this old outbuilding and it forms a U-shape following the boundaries of the lot. With the introduction of new addition:

- the back garden of the old building is completely occupied by these buildings and the height of the old outbuilding has been increased to two storeys as part of the new addition was built on top of it;

- an open courtyard has been formed to the rear of the Mansion. However, due to the increase in the density of the used space, this courtyard is now compressed and the balance of open space in proportion to the masses surrounding it has been altered and reduced;

- the building order is affected negatively as the new addition is attached to the main building. Although a respectful approach was aimed at by attaching the addition only at the corner points it was not sufficient in this case to create a detached impression.

\subsubsection{Assessment of mass properties}

The generic form of the mass of the historic building is cubical. This generic form is articulated by a pitched roof, projecting basement and symmetrical curved stairs enhance the front garden (Fig. 6). The old outbuildings are in the form of narrow, horizontal rectangular prisms to the rear. With the introduction of the new addition:

- a similar appearance to the historic building was attempted by using similar building height, roof shape, facade order and proportion of openings;

- differentiation of the old and the new is achieved by the use of architectural components in similar forms but with different details and materials. For instance, the roof of the new addition is similar in form to that of the historic building, however, it is a steel construction covered with a greenish metal sheet, while the roof of the original building is a wooden construction covered with Turkish tiles.

\subsubsection{Assessment of facades}

The entrance facade of the main building and the new addition are not facing each other and the facade of the new addition provides a background for the historic building as it is located behind the main building. With reference to the relation between the two facades (Figs. 7 and 8):

- the facade of the addition as a background is designed with reference to appearance of the openings in the historic building. The middle part, which is behind the main building, has an independent character from the historic building (Fig. 8). The facade of the side parts, being perceived as a background for the main building, is designed with reference to the facade properties of the historic building; 

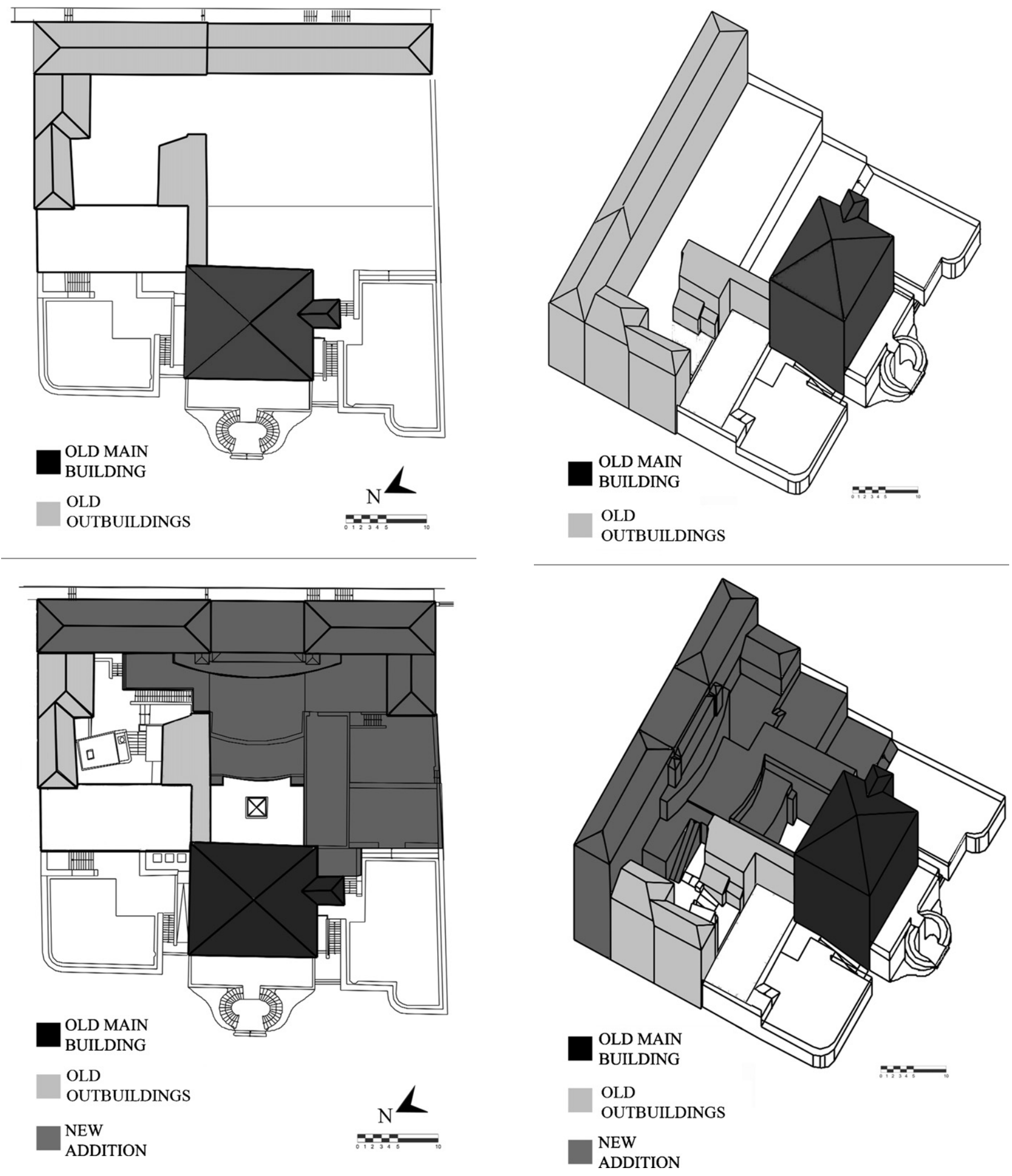

Fig. 5. The relation of the building with its site before and after addition.

Fig. 6. The relation of mass properties before and after the addition. 


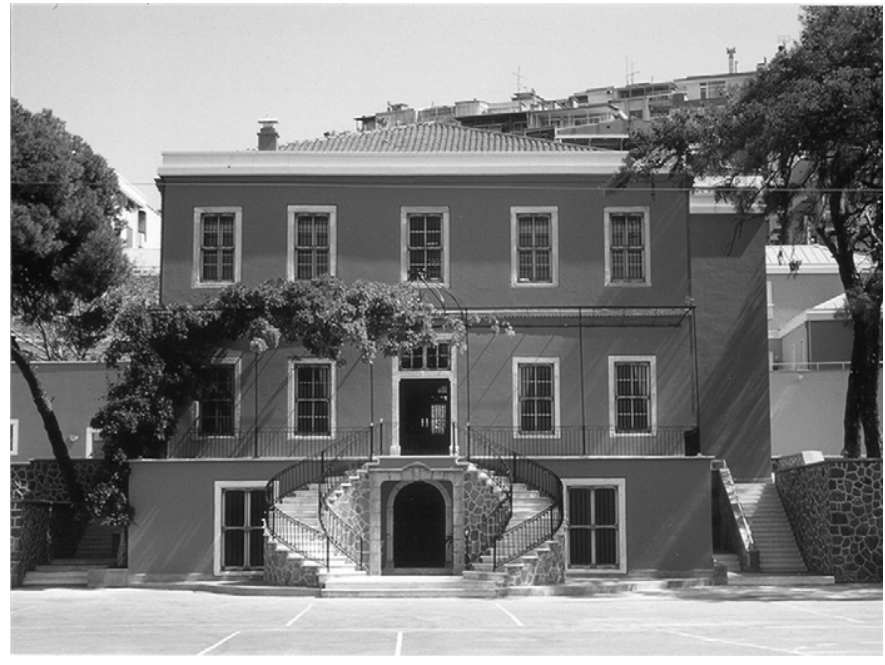

Fig. 7. The facade of the historic building.

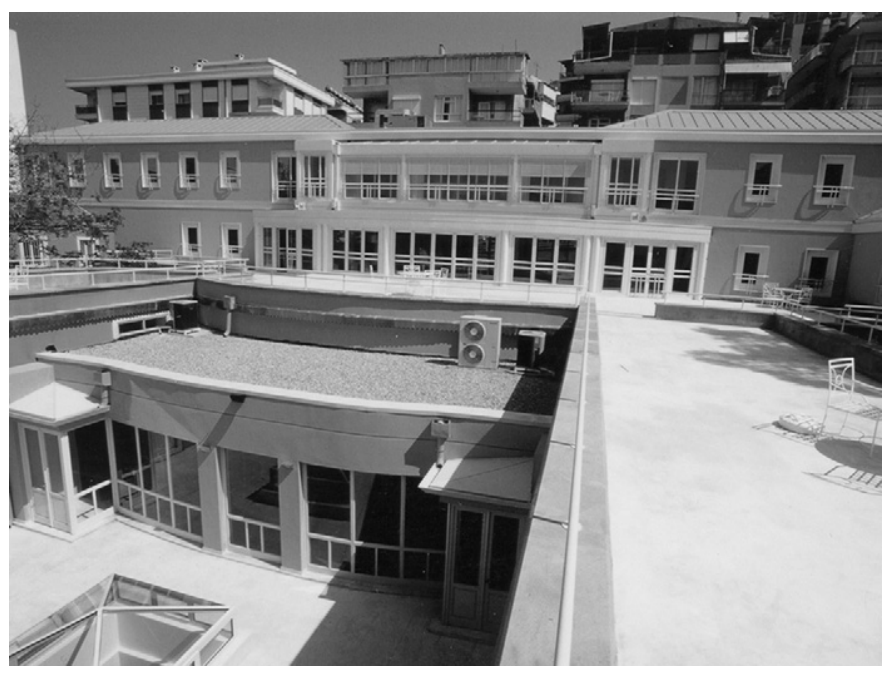

Fig. 8. The facade of new addition.

- differentiation was attempted by using different surface colours. In showing respect for the historic building, its facades are painted in a darker and more attractive colour, while the new addition is painted in a lighter colour.

\section{Evaluation}

In the context of this study, six buildings from Izmir, Turkey were studied. Five of these buildings are public buildings: Alsancak Public Hospital, Konak Public Hospital, Alsancak Train Station, the School for the Deaf and Blind and Pasaport Quay. The sixth building has been converted from a residential building to a public building. This sixth building, which is the Uşakizade Mansion, has been converted into a school building used to be a residential building in the past. The construction of a new addition to the Uşakizade Mansion came into question during the time its function has been changed. While adapting the historic building for contemporary conditions by increasing its educational potential and economic gain, the new addition was designed using a respectful approach to the value of the original building. Thus, the proportion between the size of historic building and the new addition is greater than that of the other examples. This result is directly related to the issue of the appropriateness of altering the function of a building. Since the given use requires more space and different spatial qualities than the original one, the conversion culminated in a larger addition. In this case, what the architect did to prevent the new addition from competing with the historic building was to provide a new space at the rear of the original building and to make use of the topography by locating some spaces underground, so the historic building preserves its appearance from the main pedestrian approach. On the other hand, having to concentrate all new spaces into a limited area resulted in the loss of open space at the rear, while the area in front of the building remained adequately large. The main objection to the new addition is the area it occupies at the back garden of the historic building. The new addition uses almost the whole back garden. However, the negative impact level of the new addition to the site and the setting of the historic building are balanced by the benefit it provides functionally and economically.

In considering the architectural language, the approach of the architect has been to take some features of the historic building and interpret them in a contemporary way. The architect has also used the existing outbuildings by adding a further storey. The materials used for the new architectural elements such as windows, doors, roof are clearly identified as new, although their proportions are similar to those of the historic building. For instance, the roof of the new addition is designed in the form of a hipped roof reflecting the roof shape of the historic building; however, for its construction contemporary materials were used.

On the other hand, the new addition can be evaluated as reversible. When it is removed, the original setting of the historic building can be obtained.

From the assessments of the examples, it may be concluded that the approach of architects towards the issue of new additions tends to create "harmony" through "similarity" in general, and architects also tend to use "difference" to render the new addition "distinguishable" from the original. This type of approach was identifiable in the additional buildings in the other examples except for the Pasaport Quay, where the addition appears in total contrast to the historic building. In all other examples, the concepts of similarity and abstraction were used in different aspects of the new design.

\section{Conclusion}

This assessment method can provide architects with an approach for designing new additions and in the evaluation of the existing new additions to historic buildings. Moreover, the proposed method may be taken into consideration as a scientific assistance to local governments to evaluate particular projects of cultural heritage assets. Besides, the developed method can be regarded as a contribution to the emerging field of heritage impact assessments. In this framework, historic values of a building as an architectural product of the past should clearly be identified and a new addition should bear the identity of its own period while maintaining the integrity of the original building. In this context, a new addition should be distinguishable from the old, however; it should preserve the characteristics of historic building. Therefore, it should be compatible in size, scale, colour and material with the character of the historic building.

\section{Acknowledgements}

The authors would like to thank to reviewers for their valuable comments and Cengiz Kabaoğlu, KA-BA Architecture, who provided the projects of the sample building.

\section{References}

[1] F.G. Matero, The conservation of immovable cultural property: ethical and practical dilemmas, J. Am. Inst. Conserv. 32 (1993) 15-21. 
[2] S. Demel, Preservation, historic significance and a theory of architectural additions: the canon and its consequences, Master thesis, Columbia University, USA, 1996.

[3] Z.N. Guzmán Torres, Historic buildings and contemporary additions: the elements of a cohesive design relationship, Master thesis, University of Maryland, USA, 2009.

[4] H. Yüceer, An evaluation of interventions in architectural conservation: new exterior additions to historic buildings, Ph. D. thesis, Izmir Institute of Technology, Izmir, Turkey, 2005.

[5] H. Yüceer, B. İpekoğlu, An analytical approach for the assessment of new exterior additions to historic buildings, in: G. Arun (Ed.), Proceedings of the international symposium on studies on historical heritage, Antalya, September 17-21, Yıldız Technical University Press, Istanbul, 2007, pp. 91-98.

[6] P.H. Smith, P.H. Smeallie, New construction for older buildings, Wiley, New York, 1990.

[7] J. Strike, Architecture in conservation, Routledge, London, 1994.

[8] P.S. Byard, The architecture of additions: design and regulations, W.W. Norton and Company Inc, New York, 1998.

[9] S.W. Stewen, Differentiated and compatible. http://www.traditionalbuilding.com/Previous-Issues-09/FebruaryFeature09.html, 2009 (accessed August 2011).

[10] Venice Charter. http://www.icomos.org/venice_charter.html, 1964 (accessed August, 2011).

[11] A.E. Grimmer, K.D. Weeks, Preservation brief 14: New exterior additions to historic buildings: preservation concerns, Technical Preservation Services,
National Park Service, U.S. Department of the Interior, Washington, D.C. available at: http://www.nps.gov/history/hps/tps/briefs/brief14.htm (accessed August, 2011).

[12] ICOMOS Guidance on heritage impact assessments for cultural world heritage properties. http://www.international.icomos. org/world_heritage/HIA_20110201.pdf, 2011 (accessed August, 2011).

[13] C. Norberg-Schulz, Genius loci: towards a phenomenology of architecture, Rizzoli International Publications, NewYork, 1980.

[14] F.D.K. Ching, C. Binggeli, Interior design illustrated, Wiley, Boston, 2004.

[15] H.G. Baker, Design strategies in architecture: an approach to the analysis of form, Taylor and Francis, New Orleans, 1996.

[16] L.H. Nelson, Preservation brief 17: Architectural character: identifying the visual aspects of historic buildings as an aid to preserving their character, Preservation Assistance Division, National Park Service, U.S. Department of the Interior, Washington, D.C., available at: http://www.nps.gov/history/hps/tps/briefs/brief17.htm (accessed August, 2011).

[17] P. Von Meiss, Elements of architecture: from form to place, E.F. Spon, London, 1990.

[18] S. Unwin, Analysing architecture, Routledge, New York, 1997.

[19] D. Highfield, The construction of new buildings behind historic facades, E. And F.N. Spon, Chapman and Hall, London, 1991.

[20] The Nara Document on Authenticity. http://whc.unesco.org/archive/nara94.htm, 1994 (accessed August 2011) 